\title{
Production of Indole-3-Acetic Acid by Enterobacter sp. DMKU-RP206 Using Sweet Whey as a Low-Cost Feed Stock ${ }^{\mathrm{S}}$
}

\author{
Nantana Srisuk ${ }^{1,2 *}$, Varunya Sakpuntoon ${ }^{1}$, and Pumin Nutaratat ${ }^{1,2}$ \\ ${ }^{1}$ Department of Microbiology, Faculty of Science, Kasetsart University, Chatuchak, Bangkok 10900, Thailand \\ ${ }^{2}$ Center for Advanced Studies in Tropical Natural Resources, NRU-KU, Kasetsart University, Chatuchak, Bangkok 10900, Thailand
}

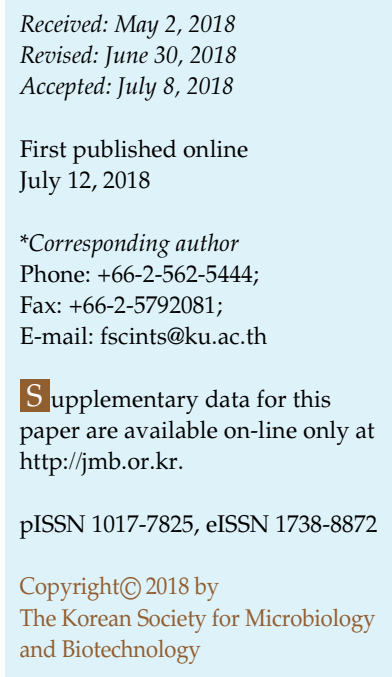

In this study, we investigated Indole-3-acetic acid (IAA) production by a rice phylloplane bacteria, Enterobacter sp. DMKU-RP206, using sweet whey as a feed stock instead of lactose. We succeeded in using sweet whey for Enterobacter sp. DMKU-RP206 to produce 3,963.0 mg IAA/ 1 with the optimal medium containing $1.48 \%$ sweet whey, $1.42 \%$ yeast extract and $0.88 \%$ L-tryptophan. The medium $\mathrm{pH}$ was adjusted to 6 and the culture conditions were shaking at $200 \mathrm{rpm}$ on an orbital shaker at $30^{\circ} \mathrm{C}$ for 3 days. We also evaluated the effect of IAA in culture filtrates of Enterobacter sp. DMKU-RP206 on the promotion of jasmine rice growth in a pot experiment. Compared with the negative control (without IAA), the result showed that biosynthetic IAA produced by Enterobacter sp. DMKU-RP206 significantly increased the growth of jasmine rice (Oryza sativa L. cv. KDML105) in terms of length and dry weight of shoot. This work thus reveals the impact of IAA produced by Enterobacter sp. on the promotion of jasmine rice growth.

Keywords: Indole-3-acetic acid, Enterobacter, sweet whey, plant growth promotion, jasmine rice

\section{Introduction}

Rice (Oryza sativa L.) is an important food crop worldwide, particularly in Asia. Thai rice, especially the variety of Khao Dawk Mali 105 (KDML105), is famous worldwide. Khao Dawk Mali Thai rice is commonly known in food markets as "Jasmine Rice," due to its shiny white color like a jasmine flower and its soft and tender texture with an aromatic fragrance when cooked. The demand for jasmine rice (O. sativa L. cv. KDML105) in the markets is increasing year by year. Hence, it is worth focusing on the promotion of jasmine rice growth.

Several studies have shown that Enterobacter can promote plant growth both in dicot and monocot [1-5]. It has therefore been claimed that Enterobacter is one of the bacteria that promote plant growth through either direct or indirect mechanisms. This was supported by the study of the draft genome of Enterobacter spp., which showed interactions between the bacteria and plant [6-9]. The genome of Enterobacter consists of genes coding for putative proteins involved with oxidative stress, nutrient uptake, root adhesion and colonization. The bacteria produced siderophore, 2phenylethanol and 4-hydroxybenzoate to protect plants against bacterial and fungal infections. Moreover, the bacteria also produced acetoin and 2,3-butanediol to promote plant growth [6].

Indole-3-acetic acid (IAA) is recognized as the key plantgrowth-promoting substance that regulates plant physiological and developmental functions. It has been shown that Enterobacter spp. produced a wide range of $5.6 \mathrm{mg}$ IAA/1 [10] - $382.2 \mathrm{mg}$ IAA/1 [11]. However, the cost of the carbon source for bacterial growth is a key factor that influences the price of any IAA produced. The use of cheap carbon sources, in particular those generated from industrial or agricultural by-products, will save production costs. Lowcost substrates, e.g. cassava fibrous residue and chickpea have been used for this purpose $[12,13]$.

Whey, a by-product from the dairy industry, is classified into two types according to the method of casein coagulation: sweet whey (rennet-induced coagulation) with $\mathrm{pH}$ of about 6.0-6.5, and acid whey (isoelectric precipitation) with $\mathrm{pH}$ of about 4.5 [14]. Sweet whey contains $70 \%$ lactose, $12 \%$ 
proteins, $1.5 \%$ fat, $8.5 \%$ other solids and $4 \%$ moisture [15]. As the lactose content in whey causes pollution, one possible way of reducing such lactose content is microbial whey fermentation. Sweet whey was used as a substrate for fermentation of various products such as ethanol [16], lactobionic acid [17] and galactooligosaccharides [18]. These reviews suggested that sweet whey is an interesting alternative substrate for microbial biotechnology. However, there has not yet been any report on IAA production from sweet whey. This study thus investigated the usage of sweet whey as an alternative substrate for IAA production by Enterobacter sp. DMKU-RP206. In addition, the impact of bacterial IAA on the promotion of rice growth was also evaluated.

\section{Materials and Methods}

\section{Microorganism}

The potential IAA-producing bacteria Enterobacter sp. DMKURP206 used in this study was isolated from the rice phylloplane and identified by analysis of the 16S rRNA gene sequence and multilocus sequence ( $g y r B, r p o B$, atpD, and infB genes) similarities, as described in Nutaratat et al. [19]. This bacterium was previously reported as a high IAA producer using lactose as a carbon source [19].

Optimization of Indole-3-Acetic Acid Production by Enterobacter sp. DMKU-RP206 Using Sweet Whey as a Substrate

Lactose, the carbon and energy source used in the ordinary culture media, was replaced by sweet whey powder (Lactoproducion, France) in order to minimize the cost of IAA production by Enterobacter sp. DMKU-RP206. Sweet whey composition is displayed in Table 1. To further reduce the production cost, laboratorygrade yeast extract was replaced by technical-grade yeast extract (Becton, Dickinson and Company, USA), which possesses acceptable clarity.

IAA production was optimized using the Box-Behnken design with four factors of interest which were sweet whey $(0.5-1.5 \%)$, yeast extract $(0.5-1.5 \%)$, L-tryptophan $(0.1-1 \%)$ (Reagent grade, Acros Organics, USA) and $\mathrm{pH}(6-8)$. Twenty-seven treatments were performed in $50 \mathrm{ml}$ production medium (in $250 \mathrm{ml}$ Erlenmeyer flask) and cultivated at $30^{\circ} \mathrm{C}$ on an orbital shaker at $200 \mathrm{rpm}$ (Table S1). All experiments were done in triplicate. Samples were taken during 3 days' incubation and culture supernatants were collected by centrifugation at $5,000 \times g$ for $5 \mathrm{~min}$. IAA in the culture supernatants were analyzed as described by Nutaratat $e t$ al. [20]. The regression model was determined for its adequacy using the coefficient of determination $\left(R^{2}\right)$ and the analysis of variance (ANOVA) with the lack-of-fit test. The Design Expert software version 10.0 (State-Ease, US) was used to analyze the data and draw the contour plots. The model and values obtained were validated in triplicate.
Table 1. The composition of sweet whey powder.

\begin{tabular}{lc}
\hline \multicolumn{1}{c}{ Component } & Value \\
\hline Crude protein $(\%$, min.) & 11.00 \\
Crude fat $(\%$, max.) & 1.50 \\
Crude ash (\%, min.) & 8.00 \\
Lactose (\%, max.) & 70.00 \\
Minerals & \\
Chloride (\%) & 3.50 \\
Sodium (\%) & 0.90 \\
Potassium (\%) & 2.80 \\
Calcium (\%) & 0.90 \\
Phosphorus (\%) & 0.90 \\
Iron (ppm) & 7 \\
Copper (ppm) & 2 \\
Magnesium $(\%)$ & 0.10 \\
Amino acids & \\
Lysine (\%) & 0.87 \\
Methionine + Cystine (\%) & 0.40 \\
Threonine (\%) & 0.67 \\
Tryptophan (\%) & 0.17 \\
\hline
\end{tabular}

Effect of IAA in Culture Filtrates of Enterobacter sp. DMKURP206 on the Promotion of Jasmine Rice Growth

The bacterial IAA biological activity was evaluated through the effect of IAA in culture filtrates of Enterobacter sp. DMKU-RP206 on jasmine rice (Oryza sativa L. cv. KDML105) growth. In this study, we decided to use crude biosynthetic IAA to reduce the production cost on extraction and purification of IAA product. Concerning the crude biosynthetic IAA, the effect of other components in crude biosynthetic IAA was considerably negligible because the crude IAA was serial diluted to more than 1300-fold. Therefore, the influence of other components in culture filtrates may not interfere with plant growth promoting activity. The five different treatments were set up as follows: Yoshida's solution (YS) [21] as negative control; YS + synthetic IAA (10 and $50 \mu \mathrm{g} / \mathrm{l})$ (Reagent grade, Sigma-Aldrich, USA) as positive control; and YS + biosynthetic IAA (10 and $50 \mu \mathrm{g} / \mathrm{l}$ ) as test. The rice seeds were surface-sterilized for $30 \mathrm{sec}$ with $70 \%$ ethanol, then by $1 \%$ $\mathrm{NaClO}$ for $2.5 \mathrm{~min}$ and $70 \%$ ethanol for $30 \mathrm{sec}$ again [22]. After sterilization, the sterile seeds were rinsed in sterile water three times. The last rinse water was checked for complete external disinfection. The sterile rice seeds were soaked with sterile water for 1 day and transferred onto sterilized moistened tissue paper for 1 day in order to study the seed germination. The germinated rice seeds were then planted in pots containing sand and vermiculite (2:1) in a greenhouse with natural photoperiod in Bangkok during June 2017 (atmospheric temperature $24-34^{\circ} \mathrm{C}$; https://www.accuweather.com). The sand and vermiculite were autoclaved three times at $121^{\circ} \mathrm{C}$ for $30 \mathrm{~min}$. Fifteen milliliters of 
Table 2. Analysis of variance (ANOVA) of Box-Behnken design for quadratic model.

\begin{tabular}{|c|c|c|c|c|c|}
\hline Source & Sum of squares & Degree of freedom & Mean square & $F$-value & $p$-value \\
\hline Model & 18403280.24 & 14 & 1314520.02 & 5.869 & 0.002 \\
\hline $\mathrm{X}_{1}$-Sweet whey & 1216982.60 & 1 & 1216982.60 & 5.433 & 0.038 \\
\hline $\mathrm{X}_{2}$-Yeast extract & 1268767.82 & 1 & 1268767.82 & 5.664 & 0.035 \\
\hline $\mathrm{X}_{3}$-L-tryptophan & 8989361.67 & 1 & 8989361.67 & 40.132 & 0.000 \\
\hline $\mathrm{X}_{4}-\mathrm{pH}$ & 1552076.97 & 1 & 1552076.97 & 6.929 & 0.022 \\
\hline $\mathrm{X}_{1} \mathrm{X}_{2}$ & 664.35 & 1 & 664.35 & 0.003 & 0.957 \\
\hline $\mathrm{X}_{1} \mathrm{X}_{3}$ & 1671125.91 & 1 & 1671125.91 & 7.461 & 0.018 \\
\hline$X_{1} X_{4}$ & 98658.81 & 1 & 98658.81 & 0.440 & 0.519 \\
\hline $\mathrm{X}_{2} \mathrm{X}_{3}$ & 28825.25 & 1 & 28825.25 & 0.129 & 0.726 \\
\hline $\mathrm{X}_{2} \mathrm{X}_{4}$ & 95505.72 & 1 & 95505.72 & 0.426 & 0.526 \\
\hline $\mathrm{X}_{3} \mathrm{X}_{4}$ & 2560928.53 & 1 & 2560928.53 & 11.433 & 0.005 \\
\hline$X_{1}^{2}$ & 14326.25 & 1 & 14326.25 & 0.064 & 0.805 \\
\hline$X_{2}^{2}$ & 203624.25 & 1 & 203624.25 & 0.909 & 0.359 \\
\hline$X_{3}^{2}$ & 243698.94 & 1 & 243698.94 & 1.088 & 0.317 \\
\hline$X_{4}^{2}$ & 170747.72 & 1 & 170747.72 & 0.762 & 0.400 \\
\hline Residual & 2687937.38 & 12 & 223994.78 & & \\
\hline Lack of fit & 2641282.41 & 10 & 264128.24 & 11.323 & 0.084 \\
\hline Pure error & 46654.97 & 2 & 23327.49 & & \\
\hline Cor total & 21091217.62 & 26 & & & \\
\hline
\end{tabular}

$R^{2}=0.87$

individual treatments were poured only on the first day of plantation followed by pouring $15 \mathrm{ml}$ daily of YS for 2 weeks in all treatments. After 2 weeks of cultivation, the length and dry weight of root and shoot were measured. The experiment was done in duplicate.

\section{Results}

Optimization of Indole-3-Acetic Acid Production by Enterobacter sp. DMKU-RP206 Using Sweet Whey as a Substrate

During three days' cultivation of Enterobacter sp. DMKURP206, the production of IAA was $210.6-4,054.0 \mathrm{mg} / 1$. The analysis of variance (ANOVA) is presented in Table 2. Based on the ANOVA, the $p$-values for the model $(p=0.002)$ and for lack-of-fit $(p=0.084)$ indicated that the experimental data fitted well with the model. The final response equation for IAA production is shown below:

$\mathrm{Y}=-80.04+1618.70 \mathrm{X}_{1}+4117.71 \mathrm{X}_{2}+9958.90 \mathrm{X}_{3}-1263.53 \mathrm{X}_{4}$ $+51.55 X_{1} X_{2}+2872.71 X_{1} X_{3}-314.10 X_{1} X_{4}+377.29 X_{2} X_{3}-309.04 X_{2} X_{4}$ $-1778.10 X_{3} X_{4}-207.31 X_{1}^{2}-781.58 X_{2}^{2}+1055.61 X_{3}^{2}+178.93 X_{4}^{2}$

where $Y$ is indole-3-acetic acid (mg/l), $X_{1}$ is sweet whey, $X_{2}$ is yeast extract, $X_{3}$ is L-tryptophan and $X_{4}$ is $\mathrm{pH}$.
This model was supported by the high value (0.87) of the correlation coefficient $\left(R^{2}\right)$ obtained. The $R^{2}$ value that was close to 1 implies that the strong statistical model and good response prediction were obtained [23]. The regression coefficients showed that IAA production by Enterobacter sp. DMKU-RP206 was influenced by interactions between sweet whey and L-tryptophan, and $\mathrm{pH}$ and L-tryptophan. The interactions between these variables on IAA yield were illustrated as a surface response and a contour plot (Fig. S1), which showed a significant $(p<0.05)$ effect on IAA production by this bacterium (Table 2). The results showed that high levels of sweet whey, yeast extract and L-tryptophan increased IAA yield. However, low $\mathrm{pH}$ was also found to enhance the IAA yield.

The RSM model revealed the conditions for maximum IAA production $(4,084.8 \mathrm{mg} / \mathrm{l})$ by Enterobacter sp. DMKURP206 as $1.48 \%$ sweet whey, $1.42 \%$ yeast extract, $0.88 \%$ L-tryptophan, pH 6 and 3 days' shaking on an orbital shaker at $200 \mathrm{rpm}$ and $30^{\circ} \mathrm{C}$. The experimental model was validated using the optimum conditions described above and in the production of IAA at $3,963.0 \mathrm{mg} / \mathrm{l}$ was found. A good correlation was obtained when comparing the predicted with the observed values. This implies that the RSM model 
Table 3. Effect of IAA in culture filtrates of Enterobacter sp. DMKU-RP206 on jasmine rice growth promotion.

\begin{tabular}{lccccc}
\hline \multicolumn{1}{c}{ Treatments } & No. of plants & Root length $(\mathrm{cm})$ & Shoot length $(\mathrm{cm})$ & Root dry weight $(\mathrm{g})$ & Shoot dry weight $(\mathrm{g})$ \\
\hline Yoshida's solution (Negative control) & 248 & $11.6 \pm 0.9^{\mathrm{a}}$ & $18.1 \pm 1.2^{\mathrm{a}}$ & $0.002 \pm 0.0^{\mathrm{a}}$ & $0.003 \pm 0.0^{\mathrm{a}}$ \\
YS + $10 \mu \mathrm{g} / 1$ synthetic IAA (Positive control) & 248 & $11.8 \pm 0.8^{\mathrm{a}}$ & $22.7 \pm 1.3^{\mathrm{c}}$ & $0.002 \pm 0.0^{\mathrm{a}}$ & $0.009 \pm 0.0^{\mathrm{b}}$ \\
YS + $10 \mu \mathrm{g} / 1$ biosynthetic IAA & 246 & $11.8 \pm 0.9^{\mathrm{a}}$ & $22.7 \pm 1.5^{\mathrm{c}}$ & $0.002 \pm 0.0^{\mathrm{a}}$ & $0.009 \pm 0.0^{\mathrm{b}}$ \\
YS + 50 $\mu \mathrm{g} / 1$ synthetic IAA (Positive control) & 242 & $11.6 \pm 0.9^{\mathrm{a}}$ & $18.8 \pm 1.1^{\mathrm{b}}$ & $0.002 \pm 0.0^{\mathrm{a}}$ & $0.003 \pm 0.0^{\mathrm{a}}$ \\
YS + 50 $\mu \mathrm{g} / 1$ biosynthetic IAA & 244 & $11.6 \pm 0.9^{\mathrm{a}}$ & $18.7 \pm 1.0^{\mathrm{b}}$ & $0.002 \pm 0.0^{\mathrm{a}}$ & $0.003 \pm 0.0^{\mathrm{a}}$ \\
\hline
\end{tabular}

Different superscript letters ( $\mathrm{a}, \mathrm{b}$, and $\mathrm{c})$ within the same column indicate significant difference between treatments using Duncan's multiple range test $(p<0.05)$.

can be used to describe the relationship between the IAA production and the influenced factors.

Effect of IAA in Culture Filtrates of Enterobacter sp. DMKU-RP206 on the Promotion of Jasmine Rice Growth in a Pot Experiment

Growth parameters (the length and dry weight of root and shoot) after 2 weeks' plantation were measured to assess the growth promoting ability of IAA produced by Enterobacter sp. DMKU-RP206. Table 3 shows that jasmine rice supplemented with IAA has a significantly increased length and dry weight of shoot compared with the negative control (without IAA); however, no difference was observed on the length and dry weight of root. Regarding the two different concentrations of IAA, the low concentration of IAA $(10 \mu \mathrm{g} / \mathrm{l})$ supported better jasmine rice growth both of length and dry weight of shoot than the high concentration of IAA $(50 \mu \mathrm{g} / 1)$. With regard to synthetic and biosynthetic IAA, a similar effect on jasmine rice growth was shown when the same concentrations of synthetic and biosynthetic IAA were used. Thus, this result indicates that IAA in culture filtrates of Enterobacter sp. DMKU-RP206 can be used instead of the synthetic IAA.

\section{Discussion}

Indole-3-acetic acid (IAA) possesses both positive and negative effects on plants depending on the dose used and kind of plant. Regarding the positive effect, IAA stimulates division, elongation and differentiation of cells including growth of fruit [24]. Regarding the negative effect, IAA can inhibit plant growth by stimulation of ethylene production, which causes stress conditions [25]. These indicate that IAA, at its optimal level, is essential to promote plant growth. IAA was produced by various microorganisms i.e. bacteria [26], actinomycetes [27], cyanobacteria [28], yeasts [20] and fungi [29]. Regarding IAA production, most IAA production by microorganisms has used a synthetic medium. Only a few reports have shown the use of alternative low-cost materials for IAA production. For example, Peng et al. [30] used corn flour as the carbon source and soybean meal as the nitrogen source to study IAA production by Pseudomonas putida Rs-198. In addition, agro-industrial residue such as cassava fibrous residue and agro-waste substrate such as chickpea have been used to reduce costs of IAA production $[12,13]$. Sweet whey has been used as a carbon source for production of various microbial products [16-18]. However, IAA production from sweet whey has not yet been reported.

In this study, the highest amount of IAA production was $3,963.0 \mathrm{mg} / 1$ when cultivated Enterobacter sp. DMKU-RP206 in $1.48 \%$ sweet whey, $1.42 \%$ technical grade yeast extract, $0.88 \%$ L-tryptophan, $\mathrm{pH}$ was adjusted to 6 and incubated at $30^{\circ} \mathrm{C}$ for 3 days on an orbital shaker at $200 \mathrm{rpm}$. In our previous study [19], 3,804.2 $\mathrm{mg} / 1$ of IAA was obtained as the maximum IAA production in the culture medium containing $0.85 \%$ lactose, $1.3 \%$ yeast extract, $1.1 \%$ L-tryptophan, $0.4 \% \mathrm{NaCl}, \mathrm{pH}$ was adjusted to 5.8 and incubated for 5 days at $30^{\circ} \mathrm{C}$ and $200 \mathrm{rpm}$. From the result, it has been clearly shown that sweet whey can be used to replace lactose for IAA production. In addition, using sweet whey also reduced the addition of $\mathrm{NaCl}$ into the fermentation medium due to $\mathrm{NaCl}$ being contained in sweet whey. The present study is therefore revealed as a success in its reduction of both time and cost of IAA production when compared with the previous study [19]. Moreover, this study is the first report on using sweet whey as a carbon source for IAA production. Finally, we found a higher amount of IAA than that previously reported for the genus Enterobacter [10, 11].

In the pot experiment, we found that both synthetic and biosynthetic IAA promoted rice growth in terms of shoot, in particular shoot length, but had no effect on the length and dry weight of root. At low concentration of IAA $(10 \mu \mathrm{g} / 1)$, it significantly enhanced the length and dry weight of shoot, while at high concentration of IAA (50 $\mu \mathrm{g} / \mathrm{l})$ only shoot length was significantly enhanced when compared with the negative control. The result indicated 
that more than $50 \mu \mathrm{g} / 1$ of IAA may inhibit jasmine rice growth. This result was consistent with that of Leveau and Lindow [31], which indicated that the lowest concentration of IAA $(1 \mathrm{nmol} / \mathrm{l})$ significantly stimulated radish root growth compared with higher concentrations $(1 \mu \mathrm{mol} / 1$ and $1 \mathrm{mmol} / \mathrm{l}$ ) and control (without IAA). Park et al. [32] recently demonstrated that $10^{-6} \mathrm{~mol} / \mathrm{l}$ IAA significantly promoted the length and width of leaf and root length of lettuce, whereas $10^{-4} \mathrm{~mol} / 1$ IAA strongly inhibited plant growth. In addition, the present study clearly indicated that biosynthetic IAA from Enterobacter sp. DMKU-RP206 had the potential to promote jasmine rice growth similarly to commercially synthetic IAA. Thus, the biosynthetic IAA produced by Enterobacter sp. DMKU-RP206 can be used to replace a commercially synthetic IAA.

In conclusion, this study succeeded in using sweet whey as a carbon source to produce IAA by Enterobacter sp. DMKU-RP206 and the IAA produced by this bacterium showed the potentiality to promote jasmine rice growth.

\section{Acknowledgment}

This work was supported by a research grant from Kasetsart University Research and Development Institute (KURDI) to N. Srisuk (2015) and the Higher Education Research Promotion and National Research University Project of Thailand, Office of the Higher Education Commission to P. Nutaratat (2016).

\section{Conflict of Interest}

The authors have no financial conflicts of interest to declare.

\section{References}

1. Jha CK, Patel B, Saraf M. 2012. Stimulation of the growth of Jatropha curcas by the plant growth promoting bacterium Enterobacter cancerogenus MSA2. World J. Microbiol. Biotechnol. 28: 891-899.

2. George P, Gupta A, Gopal M, Thomas L, Thomas GV. 2013. Multifarious beneficial traits and plant growth promoting potential of Serratia marcescens KiSII and Enterobacter sp. RNF 267 isolated from the rhizosphere of coconut palms (Cocos nucifera L.). World J. Microbiol. Biotechnol. 29: 109-117.

3. Naveed M, Mitter B, Yousaf S, Pastar M, Afzal M, Sessitsch A. 2014. The endophyte Enterobacter sp. FD17: a maize growth enhancer selected based on rigorous testing of plant beneficial traits and colonization characteristics. Biol. Fert. Soils 50: 249-262.
4. Jetiyanon K. 2015. Multiple mechanisms of Enterobacter asburiaestrain RS83 for plant growth enhancement. Songklanakarin J. Sci. Technol. 37: 29-36.

5. Li Y, Wang Q, Wang L, He LY, Sheng XF. 2016. Increased growth and root $\mathrm{Cu}$ accumulation of Sorghum sudanense by endophytic Enterobacter sp. K3-2: Implications for Sorghum sudanense biomass production and phytostabilization. Ecotox. Environ. Safety 124: 163-168.

6. Taghavi S, van der Lelie D, Hoffman A, Zhang YB, Walla MD, Vangronsveld J, Newman L, Monchy S. 2010. Genome sequence of the plant growth promoting endophytic bacterium Enterobacter sp. 638. PLoS Genet. 6: e1000943.

7. Witzel K, Gwinn-Giglio M, Nadendla S, Shefchek K, Ruppel S. 2012. Genome sequence of Enterobacter radicincitans DSM16656T, a plant growth-promoting endophyte. J. Bacteriol. 194: 5469.

8. Coulson TJ, Patten CL. 2015. Complete genome sequence of Enterobacter cloacae UW5, a rhizobacterium capable of high levels of indole-3-acetic acid production. Genome Announc. 3: e00843-15.

9. Yaish MW. 2016. Draft genome sequence of endophytic bacterium Enterobacter asburiae PDA134, isolated from date palm (Phoenix dactylifera L.) roots. Genome Announc. 4: e00848-16.

10. Madhaiyan M, Poonguzhali S, Lee JS, Saravanan VS, Lee KC, Santhanakrishnan P. 2010. Enterobacter arachidis sp. nov., a plant-growth promoting diazotrophic bacterium isolated from rhizosphere soil of groundnut. Int. J. Syst. Evol. Microbiol. 60: 1559-1564.

11. Bose A, Kher M, Nataraj M, Keharia H. 2016. Phytostimulatory effect of indole-3-acetic acid by Enterobacter cloacae SN19 isolated from Teramnus labialis (L. f.) Spreng rhizosphere. Biocatal. Agric. Biotechnol. 6: 128-137.

12. Swain MR, Ray RC. 2008. Optimization of cultural conditions and their statistical interpretation for production of indole3-acetic acid by Bacillus subtilis CM5 using cassava fibrous residue. J. Sci. Ind. Res. 67: 622-628.

13. Sudha M, Gowri RS, Prabhavathi P, Astapriya P, Devi SY, Saranya A. 2012. Production and optimization of indole acetic acid by indigenous micro flora using agro waste as substrate. Pak. J. Biol. Sci. 15: 39-43.

14. Jelen P. 2011. Whey processing, pp. 731-743. In Fuquay JW, Fox PF, McSweeney PLH (eds.), Encyclopaedia of Dairy Sciences, 2nd Ed. Academic Press, London, UK.

15. U.S. Dairy Export Council. 2004. Reference Manual for US Whey and Lactose Products. Available from http://www. thinkusadairy.org/assets/documents/Customer\%20Site/C3Using\%20Dairy/C3.7-Resources\%20and\%20Insights/02-Product\% 20Resources/ReferenceManualForWheyAndLactose_English1. pdf. Accessed 2 May 2018.

16. Leite AR, Guimarães WV, Araújo EFD, Silva DO. 2000. Fermentation of sweet whey by recombinant Escherichia coli K011. Braz. J. Microbiol. 31: 211-214.

17. Alonso S, Rendueles M, Díaz M. 2011. Efficient lactobionic acid production from whey by Pseudomonas taetrolens under 
pH-shift conditions. Bioresource Technol. 102: 9730-9736.

18. Fischer C, Kleinschmidt T. 2015. Synthesis of galactooligosaccharides using sweet and acid whey as a substrate. Int. Dairy. J. 48: 15-22.

19. Nutaratat P, Monprasit A, Srisuk N. 2017. High-yield production of indole-3-acetic acid by Enterobacter sp. DMKURP206, a rice phyllosphere bacterium that possesses plant growth-promoting traits. 3 Biotech 7: 305.

20. Nutaratat P, Srisuk N, Arunrattiyakorn P, Limtong S. 2014. Plant growth-promoting traits of epiphytic and endophytic yeasts isolated from rice and sugar cane leaves in Thailand. Fungal Biol. 118: 683-694.

21. Yoshida S, Forno DA, Cock JH, Gomez KA.1976. Laboratory manual for physiological studies of rice, 3rd Ed. International Rice Research Institutes, Los baños, Laguna, Philippines.

22. Herrera SD, Grossi C, Zawoznik M, Groppa MD. 2016. Wheat seeds harbour bacterial endophytes with potential as plant growth promoters and biocontrol agents of Fusarium graminearum. Microbiol. Res. 186: 37-43.

23. Myers RH, Montgomery DC. 1995. Response Surface Methodology: Process and Product Optimization Using Designed Experiments, Wiley-Interscience, New York.

24. Teale WD, Paponov IA, Palme K. 2006. Auxin in action: signaling, transport and the control of plant growth and development. Nat. Rev. Mol. Cell. Biol. 7: 847-859.

25. Arshad M, Saleem M, Hussain S. 2007. Perspectives of bacterial ACC deaminase in phytoremediation. Trends Biotechnol.
25: 356-362.

26. Ozdal M, Ozdal OG, Sezen A, Algur OF, Kurbanoglu EB. 2017. Continuous production of indole-3-acetic acid by immobilized cells of Arthrobacter agilis. 3 Biotech. 7: 23.

27. Harikrishnan H, Shanmugaiah V, Balasubramanian N. 2014. Optimization for production of indole acetic acid (IAA) by plant-growth-promoting Streptomyces sp. VSMGT1014 isolated from rice rhizosphere. Int. J. Curr. Microbiol. Appl. Sci. 3: 158-171.

28. Ahmed M, Stal LJ, Hasnain S. 2014. Biofilm formation and indole-3-acetic acid production by two rhizospheric unicellular cyanobacteria. J. Microbiol. Biotechnol. 4: 1015-1025.

29. Bose A, Shah D, Keharia H. 2013. Production of indole-3acetic-acid (IAA) by the white rot fungus Pleurotusostreatus under submerged condition of Jatropha seedcake. Mycology 4: 103-111.

30. Peng Y, He Y, Wu Z, Lu J, Li C. 2014. Screening and optimization of low-cost medium for Pseudomonas putida Rs198 culture using RSM. Braz. J. Microbiol. 45: 1229-1237.

31. Leveau JH, Lindow SE. 2005. Utilization of the plant hormone indole-3-acetic acid for growth by Pseudomonas putida strain 1290. Appl. Environ. Microb. 71: 2365-2371.

32. Park JM, Radhakrishnan R, Kang SM, Lee IJ. 2015. IAA producing Enterobacter sp. I-3 as a potent bio-herbicide candidate for weed control: A special reference with lettuce growth inhibition. Indian J. Microbiol. 55: 207-212. 